\title{
Válvula mecânica em carbono, de disco basculante, com revestimento de material biológico: princípios e desenvolvimento
}

\author{
Hélio Pereira de MAGALHÃES *, Ana Lúcia MACHADO *, Artur J. RAOUL *, Ary Fernandes \\ SOUTELLO FILHO * , Jairo VAIDERGORN *, José Alberto dos SANTOS * ${ }^{*}$ Márcia Valéria A. P. \\ SOUZA *, Maria Paula CRUZ *
}

RBCCV 44205-276

MAGALHÃES, H. P.; MACHADO, A. L.; RAOUL, A. J.; SOUTELLO FILHO, A. F.; VAIDERGORN, J.; SANTOS, J. A.; SOUZA, M. V. A. P.; CRUZ, M.P. - Válvula mecânica em carbono, de disco basculante, com revestimento de material biológico: princípios e desenvolvimento. Rev. Bras. Cir. Cardiovasc., $10(4): 180-189,1995$.

RESUMO: Introdução: após estudo experimental de implante de material biológico e carbono em átrio esquerdo e aorta, foi desenvolvida uma nova prótese, primeira válvula de carbono feita inteiramente no País. A finalidade foi conseguir uma válvula de sistema mecânico durável, de boa aceitaçāo orgânica para facilitar a cicatrização a partir do anel e isolar o máximo de material sintético da corrente sangũínea; o objetivo é conseguir menores índices de morbidade e mortalidade, alterando a história natural da prótese mecânica em relação a trombose, tromboembolismo, reoperações e menor uso de anticoagulante.

Material e Métodos: a válvula é do tipo disco basculante perfurado, fabricada em Carbolite (carbono polimérico endurecido). O anel apresenta haste com pino central para guiar e reter a movimentação do disco, batente e dois pinos para limitação do grau de abertura. $O$ anel tem perfuraçōes para fixaçāo do material biológico (pericárdio e veia). O conjunto é colocado entre dois anéis lisos acoplados revestidos de Poliester com aba de sutura externa. O batente tem aspecto denteado, formando plataformas onde se apóia o disco e entre os dentes existe continuidade do revestimento biológico. A prótese é toda revestida, exceto o pino, o disco, as plataformas do batente e a face interna do orifício menor. A prótese foi testada em duplicador de pulso em teste equivalente a dez anos, sem desgaste aparente com disco de carbono e poliacetal. Cada prótese, antes do implante, é testada individualmente durante cinco dias a 1.000 pulsações por minuto com pressão média de $12 \mathrm{cmHg}$. Entāo, é feita limpeza, esterilização, revestimento de material biológico processado em glicerina, montagem e esterilização final em formol ou gás ETO (conservação em glicerina). Existem 7 pacientes mitrais em observação com tempo médio de 7,8 meses (mínimo de 4 meses e máximo de 13 meses), sendo mantidos com anticoagulaçāo oral.

Resultados iniciais: como o número de pacientes é pequeno, destacam-se apenas algumas observações iniciais: ausência de tromboembolismo, ausência de disfunçāo mecânica primária, ocorrência de dois acidentes hemorrágicos maiores e um episódio de trombose em paciente com dois meses de evolução, por anticoagulação inadequada, com reoperação e mantendo a mesma prótese com achado de depósito difuso de fibrina e boa evolução após dez meses.

Conclusões: os resultados dos testes mecânicos do material e da válvula e os aspectos clínicos iniciais são favoráveis, devendo-se ampliar a casuistica, com proteção anticoagulante mais efetiva e uniforme nos três primeiros meses. Após três meses, a presença do material biológico e as baixas doses de anticoagulante parecem ser eficientes no controle das complicaçōes pós-operatórias da válvula mecânica, contra a trombose, o tromboembolismo e os acidentes hemorrágicos.

DESCRITORES: Próteses valvulares cardiacas, biológicas.

Trabalho realizado na Faculdade de Medicina da Universidade de Santo Amaro, SP, Brasil.

Recebido para publicação em novembro de 1995.

* Da Faculdade de Medicina da Universidade de Santo Amaro.

Endereço para correspondência: Hélio Pereira de Magalhães. Rua José Neves, 1139. Vila São Paulo. CEP: 04650-142 São Paulo, SP, Brasil. Tel. [011] 562.0167. 
MAGALHĀES, H. P.; MACHADO, A. L.; RAOUL, A. J.; SOUTELLO FILHO, A. F.; VAIDERGORN, J.; SANTOS, J. A.; SOUZA, M. V.A.P.; CRUZ, M.P. - Válvula mecânica em carbono, de disco basculante, com revestimento de material biológico: princípios e desenvolvimento. Rev. Bras. Cir. Cardiovasc., 10 (4): 180-189, 1995.

\section{INTRODUÇÃO}

A válvula cardíaca mecânica em posição atrioventricular apresenta uma incidência maior de tromboembolismo e trombose, devido aos fenômenos de cicatrização em torno da válvula e ao depósito de fibrina e elementos figurados do sangue sobre a sua estrutura. Esse processo reveste a válvula, isolando-a da corrente sangüínea e, assim, o depósito de partículas e o crescimento de coágulos acaba por embolisar ou trombosar a mesma. Esse processo tem sido parcialmente controlado pelo uso crônico de anticoagulante, o que adiciona uma nova complicação, que é o acidente hemorrágico. Várias idéias e tentativas têm sido propostas para proteção da válvula, ou favorecer a formação de novo endotélio.

DIAZ et alii ${ }^{10}$ revestiram a face atrial de válvula mitral com o próprio pericárdio de cães, apenas para aperfeiçoamento técnico, sem pretender sobrevivência. BRAUNWALD \& BONCHEK ${ }^{7,8}$ e BEALL Jr. et alii ${ }^{1}$ propuseram o revestimento da válvula mecânica com tecido sintético de Teflon ou Poliéster. Apesar da porosidade do tecido ter permitido invasão celular com o revesestimento por neoendotélio, houve rotura nos pontos de átrio. Mc GREGOR et alii ${ }^{17}$ aplicaram um revestimento de microesferas na superfície metálica da válvula, dando um aspecto poroso com invasão e fixação de células e formando um revestimento fino por uma neoíntima; os resultados experimentais foram promissores, a curto prazo.

BJÖRK et alii ${ }^{5}$, em trabalho experimental a longo prazo com o mesmo tipo de válvula, com uso de heparina até 90 dias, observaram, no anel, completa endotelização em todos os casos na face ventricular e em dois terços na face atrial. O centro do orifício e as hastes tiveram endotelização incompleta pelo alto fluxo de sangue com formação de pequenos trombos nos pontos de contato com o disco. O grupo controle com válvula polida apresentou trombos em quantidade variável nas faces atrial e ventricular do anel e não apresentou trombos nas hastes.

Entre nós, MORAES et alii ${ }^{\circ}$ implantaram válvula mecânica em posição mitral com revestimento da veia safena de 4 pacientes, com tempo de observação de até 20 dias, sendo que CYSNE et alii ${ }^{9}$ tiveram 1 caso de disfunção mecânica primária com esse tipo de válvula, no $15^{\circ}$ dia. MAGALHÃES et alii ${ }^{18}$ ". revestiram parcialmente $O$ anel de uma

Anais do $4^{2}$ Congresso Nacional de Cirurgia Cardiaca. Santos 1976. p. 16.

** Anais do XVLII Congresso da Sociedade Brasileira de Cardiologia. Săo Paulo, 1991. p. C61.

*** Anais do ICongresso Golden Cross-Igase. São Paulo, 1993.p. 38. válvula mecânica com pericárdio do paciente e implantaram em posição mitral, estando o mesmo sem complicações após quatro anos, com manutenção do tempo de protrombina de $51 \%$ em média.

MAGALHÃES et alii '.' fizeram implante experimental de carbono vítreo e peças revestidas com pericárdio heterólogo em átrio esquerdo e aorta, sem uso de anticoagulantes. $\mathrm{Na}$ análise dos botões implantados em átrio esquerdo, observaram boa cicatrização e ausência de trombos nas peças revestidas com pericárdio. Nos botões de carbono, não houve endotelização completa em 10\% dos casos e trombos vermelhos em $40 \%$ com origem na borda do neoendotélio. $\mathrm{Na}$ aorta os anéis revestidos com pericárdio tiveram $20 \%$ de trombos vermelhos e, nos de carbono, houve $50 \%$. Embora com endotelização total em $70 \%$ dos anéis de carbono, houve $30 \%$ de trombos. Os trombos observados na aorta se relacionaram com ausência de neoendotélio, presença de fios monofilamentares e recessos entre parede de aorta e a peça.

Após essas observaçōes, julgou-se que a associação dos dois tipos de materiais (sintético e biológico) na confecção de uma válvula cardíaca artificial facilitaria a sua incorporação ao organismo. O revestimento deixaria somente os locais da superfície sintética que são usados para apoio e deslocamento do disco pivotante. O ideal é ter uma prótese com a durabilidade da mecânica e a boa aceitação da biológica.

A finalidade do presente trabalho consiste em apresentar os princípios e desenvolvimento de uma válvula mecânica híbrida (primeira válvula de disco basculante inteiramente fabricada em carbono no Brasil). A prótese é quase totalmente revestida com pericárdio de porco no anel e na haste e com veia porcina nos dois pinos do anel. Para se chegar a esse estágio foi necessário desenvolver uma tecnologia de carbono, desenhar uma nova prótese e adequá-la para receber o revestimento biológico de modo seguro. Espera-se, com essa proteção, mudar a história clínica natural da válvula mecânica de disco com redução dos índices de morbidade e mortalidade com relação a trombose, tromboembolismo, acidentes hemorrágicos, hemólise e reoperaçōes.

\section{MATERIAL E MÉTODOS}

Válvula: o modelo $\mathrm{MH}-10$ é do tipo basculante de orifício central feito em Carbolite (carbono polimérico endurecido). 0 anel da válvula possui duas projeções internas no lado de entrada para orientar o disco na abertura e fechamento (Figura 1). Do lado da saída existe um arco radial com um 
MAGALHĀES, H. P.; MACHADO, A. L.; RAOUL, A. J.; SOUTELLO FILHO, A. F.; VAIDERGORN, J.; SANTOS, J. A.; SOUZA, M. V.A.P.; CRUZ, M.P. - Válvula mecânica em carbono, de disco basculante, com revestimento de material biológico: princípios e desenvolvimento. Rev. Bras. Cir. Cardiovasc., 10 (4): 180-189, 1995.

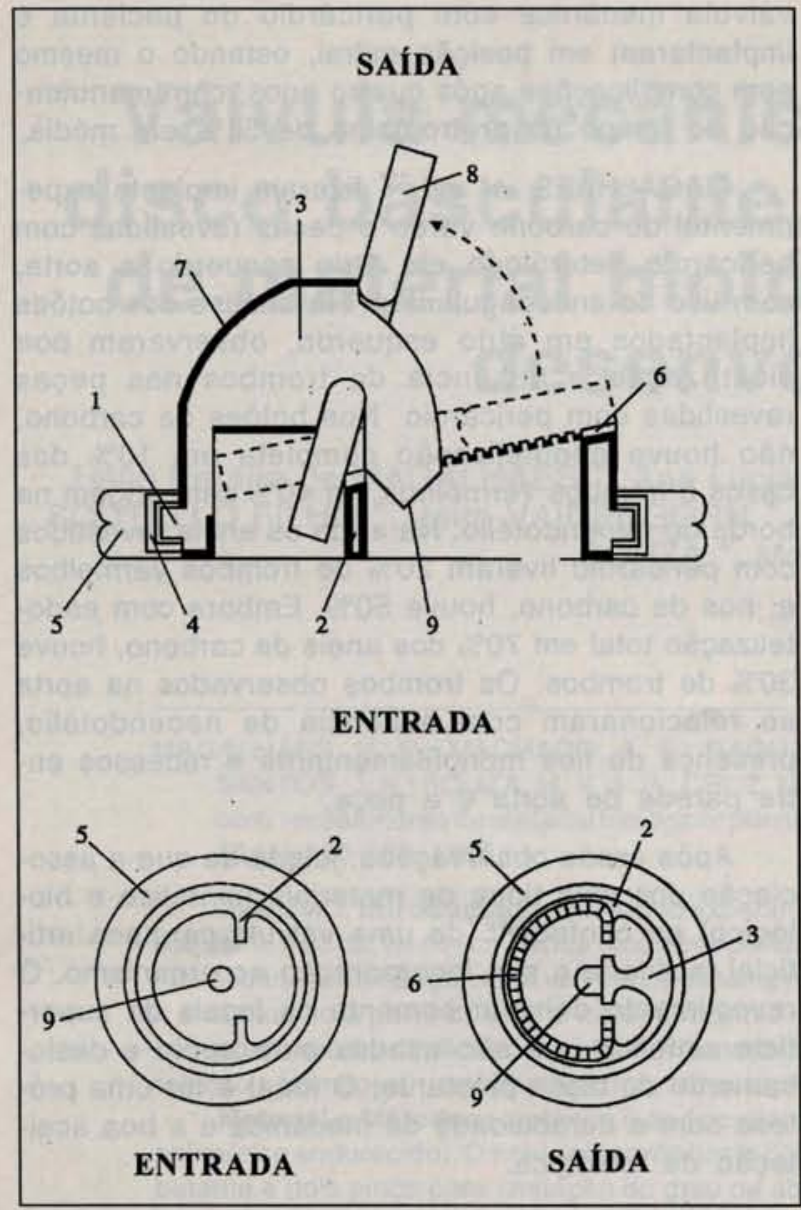

Fig. 1 - Válvula híbrida (modelo MH-10). 1: Estrutura do anel; 2: Pinos radiais; 3 : Arco radial; 4: Anel de contenção; 5 : Aba de sutura; 6: Batente denteado; 7: Revestimento biológico; 8 : Disco; 9: Pino central.

pino central que serve como guia para o disco e com um canto excêntrico que serve como apoio na abertura limitando a mesma em $75^{\circ}$. A válvula fica alojada dentro de um anel que, externamente, possui uma aba de Poliester para fixação no paciente. A área orificial útil da válvula é constituída por uma passagem maior em cuja borda do lado da saída fica o batente de fechamento do disco e uma área menor em cuja periferia existe uma folga entre o disco e o anel que permite pequeno refluxo de sangue para promover a limpeza local de eventuais depósitos de fibrina. O batente do disco é inclinado a $12^{\circ}$, mantendo a borda desprotegida do disco afastada do anel do paciente na fase de fechamento; tem o aspecto denteado, ficando o disco apoiado nas pequenas plataformas $e$, entre os dentes, ficam rebaixos para o tecido biológico que serve de ponte entre o revestimento interno e externo do anel. Esse revestimento é feito por pericárdio de porco com a face mesotelial para fora, cobrindo totalmente as faces de entrada e saída do sangue, o arco radial (exceto pino central e batente) e a passagem maior. A passagem menor é recoberta parcialmente, deixando a superfície interna em frente ao disco sem revestimento. A lâmina de pericárdio é fixada mediante sutura com fio de Polipropileno $5.0 \mathrm{em}$ orifícios na periferia do anel e base do arco radial. Os dois pinos internos do anel são revestidos com veia de porco deixando a face endotelial para fora.

Material Biológico: o pericardio e veia de porco são coletados imediatamente após abate do animal, colocados em solução fisiológica e transportados para o laboratório para limpeza e conservação em glicerina.

Teste Laboratorial: após avaliação dimensional das peças em carbono, cada válvula é testada individualmente em aparelho acelerador de pulso durante 5 dias, a 1.000 pulsações por minuto, com circulação de água a $37^{\circ} \mathrm{C}$. Então, é feita limpeza das peças, esterilização e montagem com técnica asséptica. É feito o revestimento com material biológico, conservação em glicerina e esterilização com gás óxido de etileno.

Técnica de Implante: usada técnica clássica com pontos separados em $U$, deixando a abertura maior orientada para a via de saída em posição atrioventricular; em posição aórtica, deixa-se o arco radial voltado para a válvula não coronariana (Figura 2).

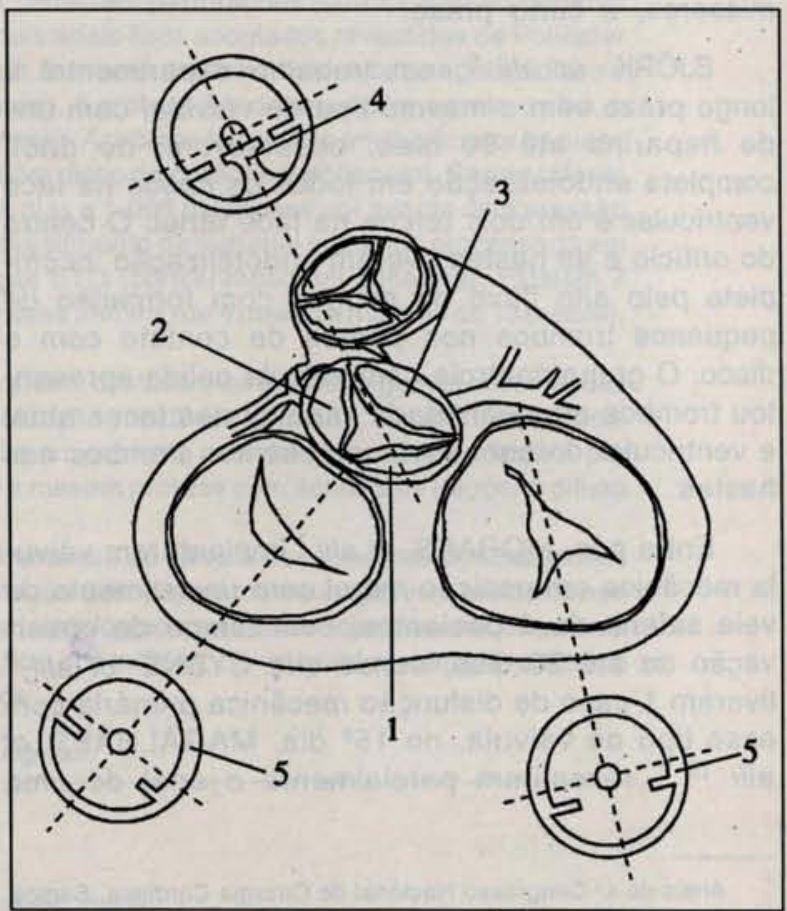

Fig. 2 - Orientação de implante em posição aórtica e mitral.1: Seio năo coronariano; 2: Seio coronariano esquerdo; 3: Seio coronariano direito; 4: Face de saída da prótese; 5 : Face de entrada da prótese. 
MAGALHÄES, H. P.; MACHADO, A. L.; RAOUL, A. J.; SOUTELLO FILHO, A. F.; VAIDERGORN, J.; SANTOS, J. A.; SOUZA, M. V.A.P.; CRUZ, M.P. - Válvula mecânica em carbono, de disco basculante, com revestimento de material biológico: princípios e desenvolvimento. Rev. Bras. Cir. Cardiovasc., 10 (4): 180-189, 1995.

TABELA 1

DIFERENÇAS FISICAS ENTRE CARBONO PIROLÍTICO E VITREO

\begin{tabular}{|c|c|c|c|c|c|}
\hline & Densidade & $\begin{array}{l}\text { Módulo } \\
\text { Young } \\
\text { (PSI) }\end{array}$ & $\begin{array}{c}\text { Tensão de } \\
\text { Energia de } \\
\text { Fratura }\end{array}$ & $\begin{array}{c}\text { Tamanho } \\
\text { do Cristal } \\
\left(A^{\prime \prime}\right)\end{array}$ & $\begin{array}{l}\text { Módulo de } \\
\text { Rotura }\end{array}$ \\
\hline $\begin{array}{l}\text { Carbono } \\
\text { Pirolítico }\end{array}$ & & & & & $\begin{array}{c}50.000 \mathrm{a} \\
100.000\end{array}$ \\
\hline $\begin{array}{l}\text { Carbono } \\
\text { Vitreo }\end{array}$ & 1 a 2,2 & 2 a $5 \times 10^{6}$ & 7 & 20 a 200 & $\begin{array}{c}20.000 \mathrm{a} \\
30.000\end{array}$ \\
\hline
\end{tabular}

Anticoagulação: iniciada por via oral a partir do $2^{\circ}$ dia de pós-operatório, procurando-se manter o tempo de protrombina em torno de $30 \%$ nos 3 primeiros meses e entre $40 \%$ e $50 \%$ a longo prazo.

Casuística: compreende 7 pacientes mitrais com tempo médio de observação de 7,8 meses (mínimo de 4 meses e máximo de 13 meses); sexo feminino (6 casos); sexo masculino ( 1 caso) média de idades de 40,4 anos (mínimo de 24 anos, máximo de 58 anos). O grau funcional era: II - 4 casos e III - 3 casos, sendo a disfunção de prótese em 3 casos, estenose mitral: em 1 caso, dupla lesão mitral: em 2 casos e insuficiência mitral: em 1 caso. Os pacientes foram submetidos à: $1^{\text {a }}$ cirurgia: 4 casos, $2^{\mathrm{a}}$ cirurgia: 1 caso, $3^{\mathrm{a}}$ cirurgia: 2 casos.

O ritmo pré-operatório era sinusal em 5 casos e fibrilação atrial em 2 casos. Existem 5 pacientes com disco de carbono e 2 pacientes com disco de poliacetal, e todos com controle recente.

\section{RESULTADOS E COMENTÁRIOS}

Carbono: O Carbolite foi testado com esse modelo de válvula em aparelho acelerador de pulso usando-se água a $37^{\circ} \mathrm{C}$, a 1.000 pulsações por minuto até 300 milhões de ciclos, tempo equivalente a 10 anos de uso clínico, sem evidenciar desgaste aparente, notando-se apenas. marca de uso nos locais de atrito. Teste comparativo com disco de poliacetal mostrou resultado semelhante com baixo coeficiente de atrito. O poliacetal foi usado como disco na válvula St. Vincents a partir de 1988, porém sem maiores informações na literatura. A maior experiência com o poliacetal foi desenvolvida na válvula de disco Björk-Shiley usada de 1969 a 1974. Os problemas referidos na literatura $3,16,20$ são relacionados à deformação do material após esterilização em autoclave. BJÖRK 2,4 , relata bons resultados com o disco de Delrin (poliacetal) calculando duração acima de 50 anos de uso; mudou para disco de Pyrolite pelo baixo desgaste, qualidades tromborresistentes e por não se alterar em autoclave.
O poliacetal teria as vantagens de ser mais leve, obedecendo melhor às variações de pressão, com estalido de fechamento mais suave e risco menor de fratura. Produz um ruído mais confortável para o paciente, porém dificulta o diagnóstico de disfunção protética em caso de trombose, já que a percepção do estalido metálico é elemento últil na ausculta. A única desvantagem real do poliacetal seria o desgaste localizado e progressivo nos pontos de contato na impossibilidade de movimentação giratória do disco. Esse movimento sempre é visto durante o teste no aparelho acelerador de pulsos em cerca de dez giros por minuto.

O Carbolite é um novo material sintético desenvolvido no País (HP Biopróteses - São Paulo) que alcança uso clínico pela primeira vez. Diferencia-se do Pyrolite (Carbomedics - Austin - EUA) cuja base estrutural é o carbono pirolítico ao qual se agrega carbeto de silício para aumentar a dureza. A base estrutural do Carbolite é o carbono vítreo em mistura com vários materiais, com a finalidade de reforçar o grau de dureza. BOKROS et alii ${ }^{6}$ determinaram as diferenças de propriedades físicas entre - carbono pirolítico e o carbono vítreo (Tabela 1). Nota-se que a resistência menor do carbono vítreo pode ser compensada pelo aumento da espessura do material. Para aumentar a resistência desses materiais ao desgaste, pode-se acrescentar materiais duros na sua composição. O Pyrolite é uma película de carbono pirolítico com carbeto de silício que reveste uma estrutura interna de grafite e o Carbolite é uma estrutura homogênea sem núcleo de grafite (Figura 3 ).

Algumas válvulas têm sido feitas unicamente de carbono pirolítico como a válvula Jyros e a válvula Bicarbon (Sorin). O carbono vítreo foi usado entre nós pela primeira vez, em trabalho experimental, por MORAES et alii ${ }^{15}$ e em aplicação clínica por OTONI et alii ${ }^{\circ}$ em válvula tipo Starr com gaiola de carbono vítreo e esfera de silicone.

\footnotetext{
* Anais do XLIII Congresso da Sociedade Brasileira de Cardiologia. Arquivos Brasileiros de Cardiologia. Vol. 49 (Supl. 1), 1987.
} 
MAGALHÃES, H. P.; MACHADO, A. L.; RAOUL, A. J.; SOUTELLO FILHO, A. F.; VAIDERGORN, J.; SANTOS, J. A.; SOUZA, M. V.A.P.; CRUZ, M.P. - Válvula mecânica em carbono, de disco basculante, com revestimento de material biológico: princípios e desenvolvimento. Rev. Bras. Cir. Cardiovasc., 10 (4): 180-189, 1995.

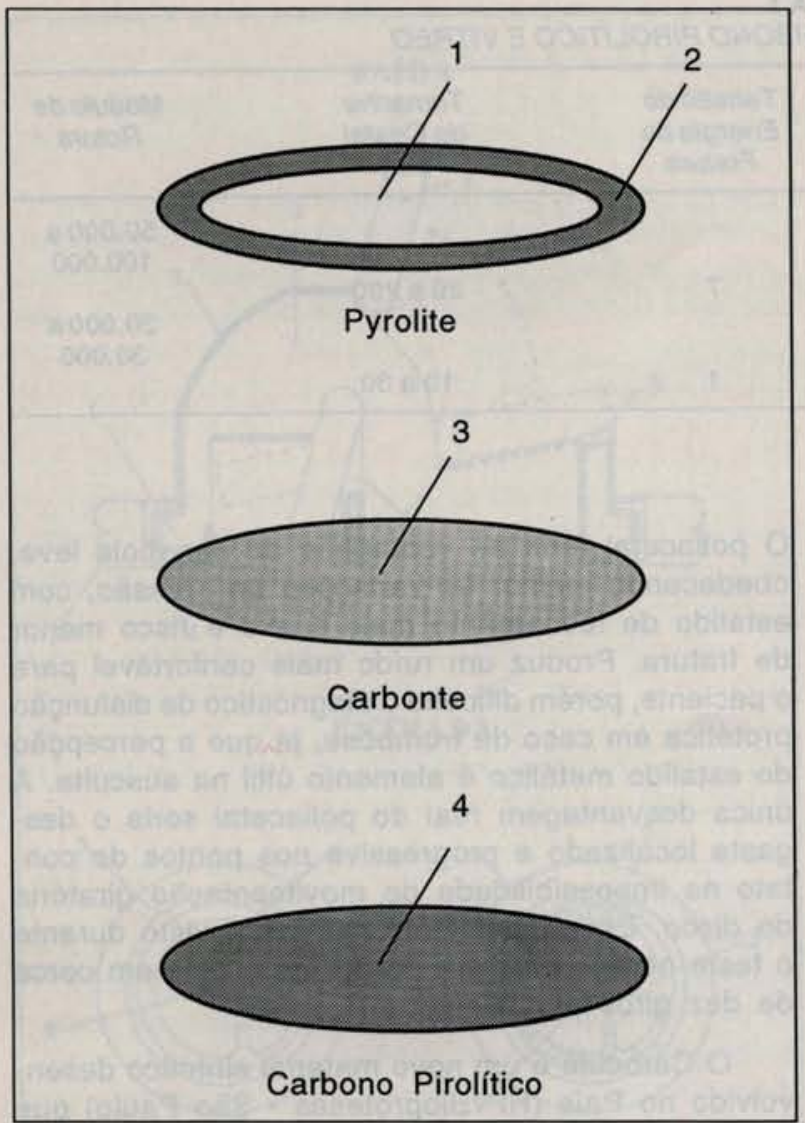

Fig. 3 - Tipos de carbono usado em válvulas. 1: Grafite; 2: Carbono pirolitico com carbeto de silicio;3: Carbono vitreo com metal duro; 4: Carbono pirolitico puro.

Válvula (Modelo MH-10): foi escolhido inicialmente o modelo de válvula mecânica de disco perfurado por duas características principais: disco guiado por pino central e movimento de afastamento do disco em relação ao anel durante a fase de abertura. Como o perímetro do disco não tem função de apoio no anel, este pode ser revestido com material biológico sem prejuízo da dinâmica da válvula. Diferenciando da Medtronic Hall, no modelo $\mathrm{MH}-10$ foram eliminados do lado da entrada o arco que sustenta o pino central, o pino radial de apoio de báscula e o batente do disco, que foram transferidos para o lado da saída (Figura 4).

Isto trouxe grande vantagem, principalmente em posição atrioventricular, porque essas estruturas obstruem a passagem do sangue do lado atrial e podem constituir locais de origem de trombos por ser o átrio zona de baixa pressão e lenta velocidade de sangue, além de redução da turbulência durante a passagem de sangue pelo orifício do anel. No entanto, perde-se uma boa característica da válvula Medtronic Hall, cuja estrutura distal de retenção do disco é aberta e, no modelo $\mathrm{MH}-10$, ela é fechada, constituída por um arco.
O disco na válvula Medtronic Hall fecha a zero graus no perímetro interno do anel $e$, no modelo $\mathrm{MH}-10$, o disco fecha em torno de $12^{\circ}$ e somente no orifício menor fica internamente no anel. No orifício maior ele se apoia no batente do anel, na sua face de saída. Esse apoio no batente é vantajoso porque a entrada de tecido no anel não ocasiona travamento dó disco; por outro lado, reduz a área orificial útil, o que é crítico somente nas válvulas de disco; por outro lado, reduz a área orificial útil, o que é crítico somente nas válvulas de menor tamanho.

Material de Resvestimento: o material biológico (pericárdio de porco) com a face mesotelial para fora reveste toda a estrutura exceto o pino central, a metade superior do orifício menor e as plataformas do denteamento do batente. Os dois pinos radiais são revestidos com veia de porco com a face endotelial para fora (Figura 1). Ideal seria 0 recobrimento total da estrutura da válvula mecânica. Os autores iniciaram a experiência com recobrimento parcial, porém ampliou-se, progressivamente, até o limite quase máximo com esse modelo de válvula. Uma válvula Medtronic Hall $n^{\circ}$ 29 apresenta cerca de 5,4 centímetros quadrados de área metálica exposta ao sangue, excluindo-se o pino central, que sofre contínua limpeza pelo disco. Essa área sofre redução de $65 \%$ no modelo $\mathrm{MH}-10$ $\mathrm{n}^{2} 29$, que tem somente 1,8 centímetros quadrados de superfície de carbono exposta.

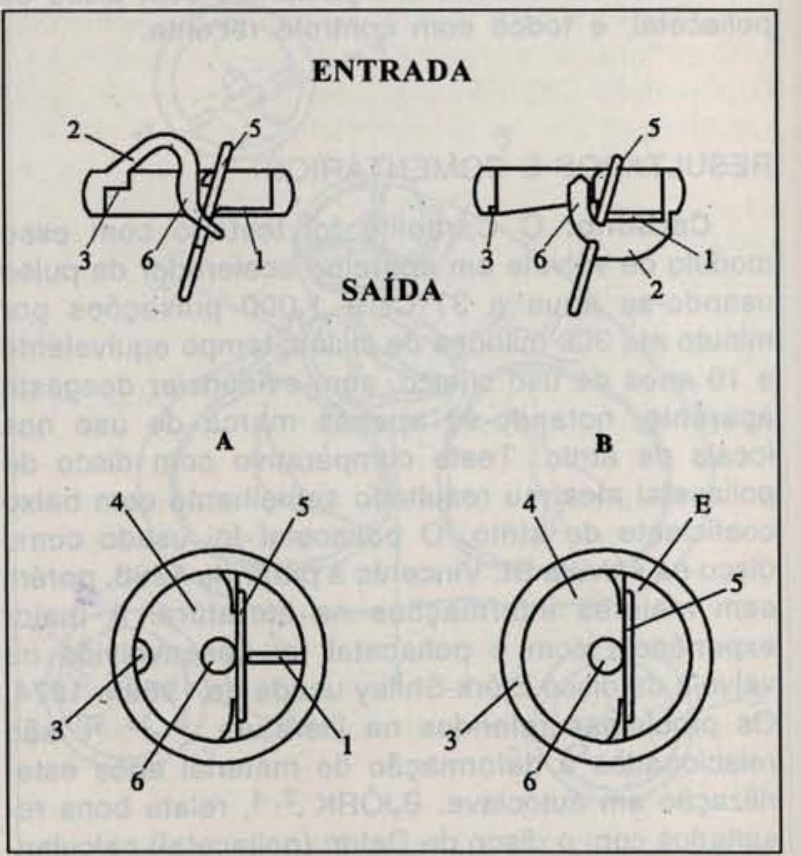

Fig. 4 - Diferenças estruturais entre a válvula Medtronic Hall (A) e 0 modelo $\mathrm{MH}-10$ (B). 1: Pino de báscula; 2: Arco radial; 3: Batente; 4: Área orificial útil; E: Espaço disco-anel com o disco aberto; 5: Disco; 6: Pino central. 
MAGALHĀES, H. P.; MACHADO, A. L.; RAOUL, A. J.; SOUTELLO FILHO, A. F.; VAIDERGORN, J.; SANTOS, J. A.; SOUZA, M. V.A.P.; CRUZ, M.P. - Válvula mecânica em carbono, de disco basculante, com revestimento de material biológico: princípios e desenvolvimento. Rev. Bras. Cir. Cardiovasc., 10 (4): 180-189, 1995.

A finalidade principal do revestimento biológico é a proteção contínua desde o lado de entrada até - lado de saída da válvula, porque o processo de cicatrização do anel tende a crescer em direção ao orifício interno da válvula. A fibrose cicatricial tende a revestir e englobar totalmente a prótese, gerando obstrução (pannus) e/ou disfunção, e pode ser o fator gerador de trombos. Nesse modelo de válvula híbrida, como o lado de entrada já está todo revestido de material biológico, a cicatrização une o anel de Poliester rapidamente ao revestimento de pericárdio, não havendo condições para organização de trombos, o que é importante, principalmente em posição atrioventricular. $\mathrm{Na}$ face de saída da válvula, as condições são mais favoráveis porque as estruturas ficam em situação intraventricular e intra-aórtica, onde as condições hemodinâmicas de alto fluxo e alta pressão desfavorecem a fixação de trombos. O local mais crítico no lado de saída é a interface entre o revestimento de pericárdio do arco e o local onde o disco se apoia quando totalmente aberto. Essa solução de continuidade com borda livre poderia ser local de desvios na cicatrização, porém é amenizada pela modelagem contínua do movimento do disco e pelas condições hemodinâmicas locais. $\mathrm{Na}$ passagem menor da área orificial existe uma faixa de carbono sem revestimento relacionada com a borda do disco em posição fechada. Pelas observações com o implante de carbono no sistema cardiovascular existe sempre neoendotelização de carbono com superfície de $2 \mathrm{~mm}$ a $3 \mathrm{~mm}$ de largura. Portanto, é previsível que haverá revestimento dessa faixa com crescimento de neoendotélio a partir dos revestimentos de pericárdio que delimitam a região acima e abaixo. Esse neoendotélio é fino e regular sem interferência com 0 movimento do disco. BJÖRK et alii ${ }^{5}$ observaram que o neoendotélio formado não aumentou de espessura no período de 6 a 18 meses.

O uso de material biológico heterólogo é mais simples, porém pode apresentar fenômenos degenerativos e o espessamento ecessivo poderá trazer disfunção. Iniciou-se a experiência com pericárdio tratado por glutaraldeído a $0,2 \%$ e conservado em formol a $4 \%$. HOFFMANN et alii ${ }^{14}$ demonstraram qualitativamente a formação de neoendotélio em todos os casos, quando o pericárdio foi tratado simplesmente por glicerina, em trabalho experimental, com observação de 32 a 288 dias de válvula mitral de pericárdio em ovelhas. Quando o pericárdio foi tratado com glutaraldeído e formol não ocorreu a endotelização em 5 dos 6 casos. Peças tratadas com glicerol e colocadas em formol tiveram retardo na endotelização. Desde o conhecimento desse trabalho, as válvulas híbridas são processadas unicamente em glicerol e complementada a esterilização com gás óxido de etileno, preferencialmente, ou formol, sendo eliminado o glutaraldeído.
FLEMMA et alii ${ }^{12}$, em análise até 16 anos, mostraram que as complicações com a válvula BjörkShiley são maiores nos dois primeiros anos, com respeito a trombose e tromboembolismo. O período mais crítico consiste nos primeiros meses, justamente por ser o período de cicatrização e de ajuste da terapêutica anticoagulante. Após seis meses, essas complicações diminuem e se tornam lineares depois do segundo ano de pós-operatório. Nos dois primeiros anos, $37,5 \%$ das complicações aconteceram no $1^{2}$ mês; $27 \%$ do $2^{\circ}$ ao $6^{2}$ mês; $9 \%$ do $7^{\circ}$ ao $12^{\circ}$ mês e $26,5 \%$ no $2^{\circ}$ ano de pós-operatório.

Nas válvulas mecânicas em geral, se a cicatrização a partir do anel de sutura for regular, e não excessiva, as possibilidades de trombose e tromboembolismo seräo menores, o que explica porque alguns pacientes têm boa evolução, mesmo sem uso de anticoagulante. Os esforços têm de ser feitos não apenas para inibir os excessos da cicatrização, mas também para direcionar e controlar de modo mais completo as forças naturais reativas do organismo, já que englobar materiais estranhos na circulação é um determinismo inexorável. Caso haja irregularidades na cicatrização, os acidentes podem ocorrer mesmo com proteção anticoagulante ideal.

A prótese mecânica em geral está sujeita ao aparecimento de tecido fibroso nas suas bordas em direção do centro, com presença ou não de trombos. A disfunção só aparece quando interfere com o movimento dos seus elementos, fechamento e abertura. A incidência desses fenômenos é difícil de precisar, devido à dificuldade de detecção por exames e dos critérios diagnósticos. Pela revisão de GONZÁLES et alii ${ }^{13}$, a disfunção da prótese por trombose pode ser de graus variáveis de evolução lenta com pacientes assintomáticos, até trombose de caráter agudo de rápida evolução com intensa e grave repercussão hemodinâmica. Como a trombose de caráter agudo em prótese biológica com disfunção é rara, talvez a introdução de material biológico na prótese mecânica diminua a incidência de fenômenos agudos ou os transforme em disfunção de evolução mais lenta com possibilidade de tratamento eletivo.

A curto prazo, a tendência parece ser de depósito de fibrina sobre o material biológico que pode levar à disfunção; nesse período, deve-se fazer intensa e completa proteção com anticoagulantes e com antiagregantes plaquetários. Após o período de cicatrização, com o estabelecimento de um neoendotélio, deverá haver redução dos índices de trombose e tromboembolismo. Como o material biológico fica imóvel, os fenômenos degenerativos deverão ser menores e diretamente relacionados ao tipo de tecido e às técnicas usadas para conservação ou fixação. IMAI et alii ${ }^{15}$ introduziram o termo 
MAGALHĀES, H. P.; MACHADO, A. L.; RAOUL, A. J.; SOUTELLO FILHO, A. F.; VAIDERGORN, J.; SANTOS, J. A.; SOUZA, M. V.A.P.; CRUZ, M.P. - Válvula mecânica em carbono, de disco basculante, com revestimento de material biológico: princípios e desenvolvimento. Rev. Bras. Cir. Cardiovasc., 10 (4): 180-189, 1995.

"biolization" (biomorfose) de superfícies sintéticas para significar o depósito inicial rápido de proteínas e sua fixação nas superfícies ou como formação tardia de neoíntima como fatores favoráveis de aumento na resistência contra a formação de trombos. O material ideal de revestimento seria o pericárdio ou veia retirados e inseridos na válvula no ato operatório. Nessa situação teríamos um enxerto vivo menos sensível a fenômenos degenerativos como espessamento, fibrose e calcificação.

Hemólise: após alta hospitalar, não ficou caracterizado clinicamente nenhum quadro de hemólise, estando todos os pacientes com hemograma normal. A maior parte da superfície da válvula está revestida com material biológico e, portanto o trauma dos glóbulos vermelhos e as folgas entre o disco e as estruturas da válvula (pino, anel), locais que podem gerar hemólise, parecem ser adequados.

A ausculta normal da prótese apresenta dois estalidos de caráter diferente: 0 de abertura de intensidade menor, timbre metálico abafado simples ou desdobrado produzido quando o disco encontra o batente do arco e se apóia nos dois pinos radiais. O estalido de fechamento de curta duração, de timbre metálico agudo, cuja intensidade é dependente do nível de pressão arterial do paciente. Quando o disco é de poliacetal, os estalidos são de baixa intensidade, não perceptíveis à distância e, à ausculta, a intensidade das bulhas é próxima do normal.

As próteses mecânicas, em geral, podem ser transformadas em válvulas híbridas, desde que adaptadas para fixação do tecido biológico. Os princípios gerais seguidos no projeto deste modelo incluem material e sistema mecânico duráveis, ausência de material biológico nos pontos de retenção da peça móvel, uso de material de baixa reatividade orgânica, ausência de material biológico próximo e por fora do perímetro da peça móvel, sistema preferencial de vedação por sobreposição, peça móvel com excursão bem livre, acoplamentos folgados que permitam espessamentos limitados do material biológico e extensão de revestimento o mais completo possivel e sem solução de continuidade acima de 2 a 3 milímetros.

Resultados Clínicos Iniciais: o número de casos é pequeno, não permitindo estudo estatístico ou comparativo. No entanto, pode-se comentar os eventos desfavoráveis e favoráveis ocorridos e fazer consideraçōes hipotéticas sobre resultados futuros. O fato mais preocupante foi a trombose de prótese mitral ocorrida com dois meses de pósoperatório, em paciente de sexo feminino, com pequena cardiomegalia e em ritmo sinusal. $O$ único fator de risco determinante trombogênico era anticoagulação inadequada no período inicial pós- implante. O tempo de protrombina era de $70 \%$ aos 40 dias de pós-operatório e, 20 dias após, apresentou cansaço progressivo com história evolutiva de uma semana, apresentando taquiarritmia e sinais de estase pulmonar. Houve retardo no diagnóstico clínico, porém a cirurgia foi eletiva, sendo conservada a válvula. $O$ achado foi de imobilização do disco com depósito de fibrina em sua volta e no arco radial e sinais de boa neoendotelização no anel de sutura. Esse aspecto com a não existência de trombos vermelhos na prótese foram os fatores determinantes da sua conservação, sendo feita retirada com facilidade da fibrina. A presença de trombos vermelhos pequenos foi notada na parede atrial e na aurícula esquerda, devendo ser secundária a estase e pressão atrial esquerda elevada. A paciente foi submetida a cirurgia na traquéia aos nove meses de pós-operatório e, apesar de muito manuseada cirurgicamente, encontra-se bem da parte cardiovascular, com ausculta normal.

Dois pacientes com episódio hemorrágico, de vias urinárias, requerendo internação com valores de tempo de protrombina em menos de $10 \%$ e $19 \%$ com 30 dias e 75 dias de pós-operatório tiveram boa evolução.

No período hospitalar, o tempo de protrombina médio ficou apenas em $65 \%$, com média geral nos três primeiros meses de $60 \%$. Após os três meses, o valor médio do tempo de protrombina foi de $51 \%$, ocorrendo 1 caso de epistaxe passageira.

Todos os resultados dos tempos de protrombina estão no Gráfico 1, mostrando anticoagulação pouco efetiva, principalmente nos três primeiros meses, quando a proteção deveria ser mais completa. Por estas evidências e pelo episódio de trombose valvular, foi estabelecido novo protocolo sugerido por DELBUSTO \& VIGO ${ }^{11}$ : heparina contínua (600 U/h) com início após 6 horas da operação mantida até retirada do dreno; heparina subcutânea (10.000 U/h) até proteção efetiva de cumarínico; cumarínico via oral na retirada do dreno com manutenção do tempo de protrombina em $22 \%$ a $30 \%$ (INR de 2,5 a 3) para aórticos, $18 \%$ a $22 \%$ (INR de 3 a 3,5) para mitrais e de $15 \%$ a $18 \%$ (INR de 3,5 a 4 ) para mitroaórticos.

Nos pacientes com dupla prótese e com fatores de risco tromboembólico, associar dipiridamol na dose de $5 \mathrm{mg} / q u i l o$ de peso.

Os eventos favoráveis foram a ausência, após - $3^{\circ}$ mês, de trombose e tromboembolismo com doses mais baixas de anticoagulante, ausência de hemólise, ausência de acidentes hemorrágicos im-

\footnotetext{
* INR: International Normalized Ratio
} 
MAGALHÄES, H. P.; MACHADO, A. L.; RAOUL, A. J.; SOUTELLO FILHO, A. F.; VAIDERGORN, J.; SANTOS, J. A.; SOUZA, M. V.A.P.; CRUZ, M.P. - Válvula mecânica em carbono, de disco basculante, com revestimento de material biológico: princípios e desenvolvimento. Rev. Bras. Cir. Cardiovasc., 10 (4): 180-189, 1995.

GRÁFICO 1

MÉDIA DOS TEMPOS DE PROTROMBINA DOS PACIENTES EM OBSERVAÇÃO

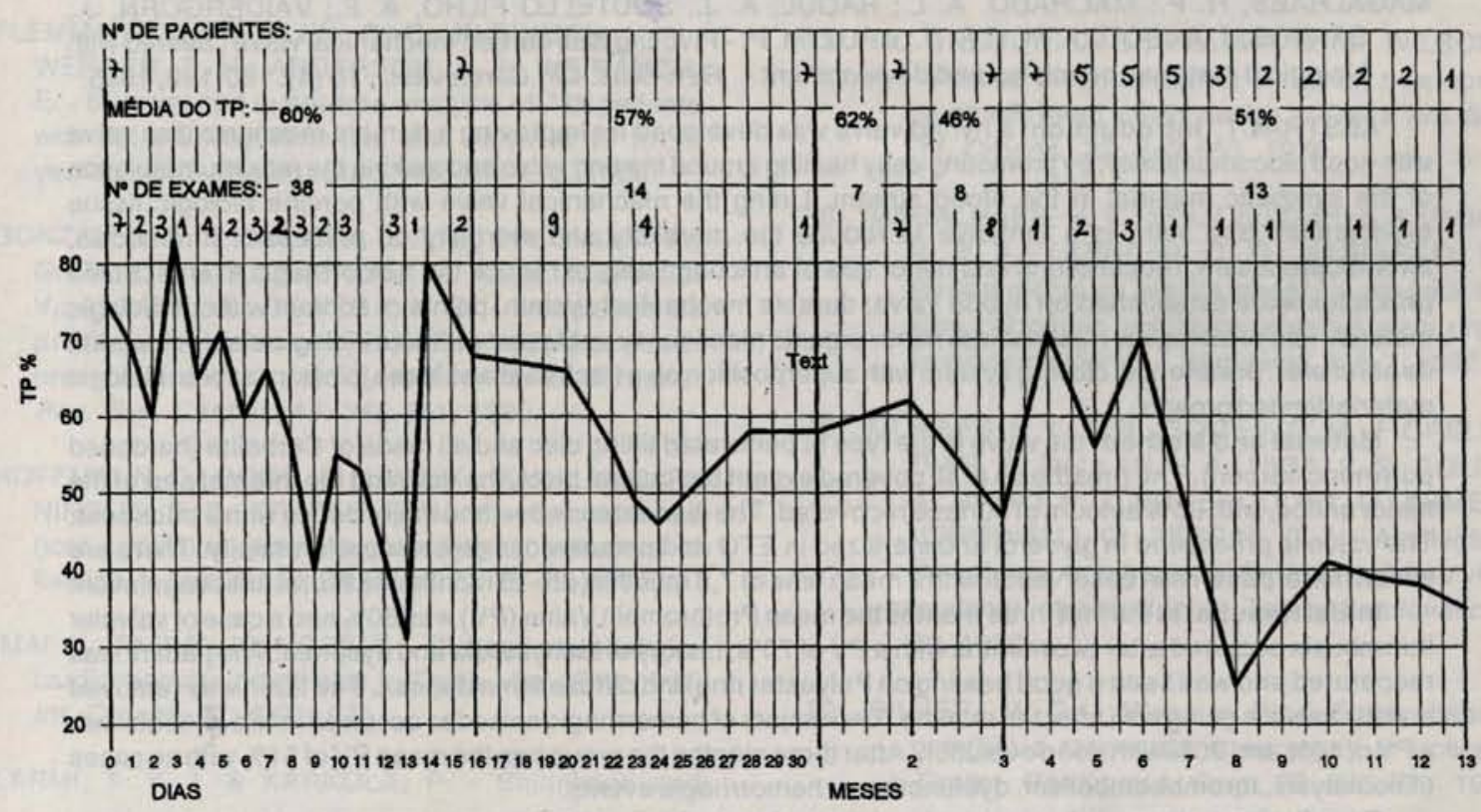

portantes e melhoria acentuada do grau funcional dos pacientes.

As conclusões sobre os estudos e observações, até o momento, incluem avaliações do Carbolite, desenho da válvula (modelo $\mathrm{MH}-10$ ), material biológico de revestimento, cicatrização e resultados clínicos iniciais. O Carbolite para esse modelo de prótese mostrou adequado teste in vitro, garantindo resistência mecânica e durabilidade suficientes para a vida do paciente. Em avaliação experimental, o carbono vítreo foi recoberto por novo endotélio quando exposto em superfícies de poucos milímetros. Quando houve aparecimento de trombos, estes não estavam aderidos à superfície do material, sendo sempre uma extensão da linha de cicatrização ou formados em recessos entre a prótese e a parede vascular. Os trombos são produzidos por um distúrbio local da linha de cicatrização, quando o endotélio não consegue revestir completamente uma superfície estranha. A função do tecido biológico de revestimento da prótese é receber essa linha de cicatrização fundindo-se com as células da cicatriz, recebendo um neoendotélio, visto que o organismo não consegue concluir esse revestimento de maneira completa em superfícies extensas das próteses com os materiais testados até o momento. A anticoagulação inicial e intensiva controla o processo de cicatrização, fazendo com que o mesmo seja mais lento e ordenado. Após a formação de neoendotélio e absorção de proteínas nas superfícies, a possibilidade de trombose e/ou tromboembolismo se reduz, podendo-se diminuir o nível de anticoagulação.

O desenho do modelo $\mathrm{MH}-10$, dimensionado para esse material, mostrou-se efetivo sob o pontode-vista funcional e sensível à dinâmica circulatória, tanto com disco de carbono como de poliacetal. A trombose valvular é fato preocupante, pelo pequeno número de casos em observação, já que foi precoce com proteção anticoagulante inadequada.

Portanto, apesar do revestimento biológico, existe a necessidade de anticoagulação intensiva nos três primeiros meses de pós-operatório. Isto pode levar, certamente, ao aparecimento de problemas hemorrágicos, exigindo um controle mais freqüente e completo do paciente. Após esse tempo, a evolução clínica dos pacientes tem sido excelente com baixa proteção anticoagulante, encorajando a continuação do uso clínico da prótese. 
MAGALHĀES, H. P.; MACHADO, A. L.; RAOUL, A. J.; SOUTELLO FILHO, A. F.; VAIDERGORN, J.; SANTOS, J. A.; SOUZA, M. V. A. P.; CRUZ, M.P. - Válvula mecânica em carbono, de disco basculante, com revestimento de material biológico: princípios e desenvolvimento. Rev. Bras. Cir. Cardiovasc., 10 (4): 180-189, 1995.

RBCCV 44205-276

MAGALHĀES, H. P.; MACHADO, A. L.; RAOUL, A. J.; SOUTELLO FILHO, A. F.; VAIDERGORN, J.; SANTOS, J. A.; SOUZA, M. V. A. P.; CRUZ, M. P. - Pivoting disc carbon mechanical valve covered with biological material: principles and development. Rev. Bras. Cir. Cardiovasc., 10 (4): 180-189, 1995.

ABSTRACT: Introduction: a hybrid valve was developed for improving a durable mechanic disc valve with good biocompatibility, by promoting easy healing around the ring valve and making the maximum isolation of the synthetic material in the blood stream. Lining the mechanical valve with porcine biologic tissue (pericardium and vein) is a tentative to reduce the morbidity and mortality on respect of thrombosis, thromboembolism, reoperations and minor use of anticoagulants to reduce the hemorrhagic events. Some principles were established on hybrid valve: durable mechanical system, points of contact without biologic material, use of biological material with minor organic reaction, movable parts without biologic material outside its perimeter, preferential closing system with superposition on a track seat and loose joints for accept biologic material limited growth.

Material and Method: the valve is the type of perforated tilting disc and all made of Carbolite (hardened polymeric carbon). The prosthesis is all covered except the central pivot, the disc and the internal part of the minor orifice, with $65 \%$ amount of surface recovered. The disc extends over themajor orifice with a track seat. The valve is processed in glycerol and sterilized in ETO and preserved in glycerol preferentially. There are seven mitral patients in observation with a mean time of 7,8 months ( 4 to 13 months) with oral anticoagulation.

Initial Results: in the first three months the mean Prothrombin Value (PV) was $60 \%$ and a case of valvular thrombosis occurred after two months with a PV of $70 \%$, history of tachycardia and dyspnea. The patient was reoperated and was seen a good healing on Polyester ring and diffuse fibrin deposit. The fibrin was removed and the valve is going well after ten months. Two majors of hemorrhagic episodes occurred in two patients with a PV of $10 \%$ and $20 \%$ with good evolution. After three months the group has the mean PV of $51 \%$ with no cases of hemolysis, thromboembolism, dysfunction or hemorrhagic events.

Conclusions: the mechanical tests of the valve and the initial clinical aspects are favorables. It is necessary to augment the number of cases with more effective and uniform anticoagulant protection in the first three months to avoid thrombosis and hemorrhagic events. After three months the biolization of the valve with low anticoagulant doses seems to be efficient.

DESCRIPTORS: Heart valves prostheses, biologic.

\section{REFERÊNCIAS BIBLIOGRÁFICAS}

1 BEALL Jr., A. C.; BLOODWELL, R. D.; LIOTTA, D.; COOLEY, D. A.; DE BAKEY, M. E. - Clinical experience with a Dacron velour-covered Teflon-disc mitral valve prosthesis. Ann. Thorac. Surg., 5:402$410,1968$.

2 BJORK, V. O. - Delrin as implant material for valve occluders. Scand. J. Thorac. Cardiovasc. Surg., 6: 103-107, 1972.

3 BJORK, V. O. - Disc wear with the Bjork-Shiley tilting disc valve. Scand. J. Thorac. Cardiovasc. Surg., 5: 87-91, 1971.

4 BJORK, V. O. - The pyrolitic carbon occluder for the Bjork-Shiley tilting disc valve prosthesis. Scand. J. Thorac. Cardiovasc. Surg., 6: 109-113, 1972.

5 BJORK, V. O.; WILSON, G. J.; STERNLIEB, J. J.; KAMINSKY, D. B. - The porous metal-surfaced heart valve: longterm study without longterm anticoagulation in mitral position in goats. J. Thorac. Cardiovasc. Surg., 95: 1067-1082, 1988.
6 BOKROS, J. C.; AKINS, R. J.; SHIM, H. S.; HAUBOLD, A. D.; AGARWAL, N. K. - Carbon in prosthethic devices. ACS Symposium Series, Number 21. Petroleum Derived Carbons., 237-265, 1975.

7 BRAUNWALD, N. S. \& BONCHECK, L. I. - Prevention of thrombus formation on rigid prosthetic heart valves by the ingrowth of autogenous tissue. J. Thorac. Cardiovasc. Surg., 54: 630-638, 1967.

8 BRAUNWALD, N. S. \& BONCHECK, L. I. - Thrombus resistant rigid prosthetic heart valve covered with porous synthetic fabric. Trans. Am. Soc. Artif. Int. Organs., 13: 101-104, 1967.

9 CYSNE, E.; MACHADO, E.; ABÍLIO, F. M.; FREITAS, E.; CUNHA, M. A.; SANTOS, E. A.; PERNAMBUCO, P.; FEITOSA, L.; VIEIRA, R.; MORAES, D. J. Escape do disco da valva mitral de safena autógena com reoperação da paciente. Arq. Bras. Cardiol., 31: $39-43,1978$.

10 díAZ, F. A.; LOUZANO, J. M.; NUNEZ, C. Y. Prevención de trombosis en protesis mitral con pericárdio. Rev. Esp. Cardiol., 21: 539-542, 1968. 
MAGALHÄES, H. P.; MACHADO, A. L.; RAOUL, A. J.; SOUTELLO FILHO, A. F.; VAIDERGORN, J.; SANTOS, J. A.; SOUZA, M. V.A.P.; CRUZ, M.P. - Válvula mecânica em carbono, de disco basculante, com revestimento de material biológico: princípios e desenvolvimento. Rev. Bras. Cir. Cardiovasc., 10 (4): 180-189, 1995.

11 DEL BUSTO, A. R. \& VIGO, A. P. - Indicaciones actuales del tratamiento antitrombótico en la enfermidad valvular. Rev. Esp. Cardiol., 44: 190-202, 1991.

12 FLEMMA, R. J.; MULLEN, D. C.; KLEINMAN, L. H.; WERNER, P. H.; ANDERSON, A. J.; WEIRAUCH, E. - Survival and event-free analysis of 785 patients with Bjork-Shiley spherical disc valve at 10 to 16 years. Ann. Thorac. Surg., 45: 258-272, 1988.

13 GONZÁLES, E. T.; MARTIN, J. A. F.; PALOMINO, P.; GARCIA, J. J. R.; BUENO, J. M. A.; ALMOZAN, A. V.; ALCADE, G.; DE VEGA, N. G. - Trombólisis de prótesis valvulares cardiacas trombosadas: presentácion de 2 casos y revisión de la literatura. Rev. Esp. Cardiol., 43: 345-351, 1990.

14 HOFFMANN, D.; GONG, G.; LIAO, K.; MACALUSO, F.; NIKOLIC, S. D.; FRATER, R. W. M. - Spontaneous host endotelial growth bioprostheses: influence of fixation. Circulation, 86 (Supl. 2): 75-79, 1992.

15 IMAI, Y.; TAJIMA, K.; NOSÉ, Y. - Biolized materials for cardiovascular prosthesis. Trans. Am. Soc. Artif. Int. Organs, 17: 6-9, 1971.

16 LARMI, T. K. I. \& KARKOLA, P. - Shirinkage and degradation of the delrin occluder in the tilting-disc valve prosthesis. J. Thorac. Cardiovasc. Surg., 68: 66-69, 1974.

17 MC GREGOR, D. C.; PILLIAR, R. M.; WILSON, G. J. - Porous metal surfaces: a radical new concept in prosthetic heart valves design. Trans. Am. Soc. Artif. Int. Organs., 22: 643-653, 1976.

18 MAGALHÄES, H. P.; SOUTELLO F, A. F.; SOUZA, M. V. P. A.; LANNI, M. C. G.; FARIAS, O. R. W. Revestimento de válvula mecânica em posição mitral com pericárdio autólogo: tentativa para prevenir o tromboembolismo. Mednews, 9: 5-7, 1992.

19 MORAES, N. L. T. B.; GOMES, O. M.; FIORELLI, A. I.; DIAS, S.; DALLAN, L. A.; HIGA, S. S.; TOLOZA, M. A.; BRITO, P. J.; BITTENCOURT, D.; ARMELIN, E.; VERGINELLI, G.; ZERBINI, E. J. - Avaliação experimental da trombogenicidade do carbono vítreo em implante intracardiaco. Torac. Cardiovasc., 1: 36 39, 1982.

20 SILVER, M. D. - Wear in Bjork-Shiley heart valve prosthesis recovered at necropsy or operation. J. Thorac. Cardiovasc. Surg., 79: 693-699, 1980. 